\title{
Nickel Removal from Aqueous Solution Using Chemically Treated Mahogany Sawdust as Biosorbent
}

\author{
Rajesh Chanda (D), Amir Hamza Mithun, Md. Abu Hasan, and Biplob Kumar Biswas $\mathbb{E}$ \\ Department of Chemical Engineering, Jashore University of Science and Technology, Jashore 7408, Bangladesh \\ Correspondence should be addressed to Biplob Kumar Biswas; bk.biswas@just.edu.bd
}

Received 30 June 2021; Revised 4 September 2021; Accepted 6 September 2021; Published 21 September 2021

Academic Editor: Abdullah Aldawsari

Copyright (c) 2021 Rajesh Chanda et al. This is an open access article distributed under the Creative Commons Attribution License, which permits unrestricted use, distribution, and reproduction in any medium, provided the original work is properly cited.

Sawdust is a waste material, which is generally produced during making furniture and other necessary wood products. With a view to utilizing this waste material, a biosorbent was prepared from mahogany (Swietenia macrophylla) sawdust through simple chemical treatment and was used to remove nickel ion $\left(\mathrm{Ni}^{2+}\right)$ from an aqueous solution. The adsorbent material was characterized by Fourier transform infrared (FTIR) spectroscopy, scanning electron microscopy (SEM), and energy dispersive X-ray (EDX) analysis. The effects of biosorbent dosage $(2 \sim 18 \mathrm{~g} / \mathrm{L}), \mathrm{pH}$ of the tested solution (4 10.5), contact time (up to $360 \mathrm{~min}$ ), and temperature $(298 \sim 318 \mathrm{~K})$ were studied in batchwise experiments. The maximum adsorption capacity of the treated sawdust was determined to be $13.42 \mathrm{mg} / \mathrm{g}$ at an optimum condition (sorbent dose of $15 \mathrm{~g} / \mathrm{L}, \mathrm{pH}$ of 9, and temperature of $298 \mathrm{~K}$ ). The experimental data extrapolation revealed that the adsorption process fitted the Langmuir isotherm model and the kinetics was a pseudo-second-order kinetic model. The obtained thermodynamic parameters indicated that the adsorption reaction was spontaneous, endothermic, and random in nature. The study revealed that sawdust biosorbent has potential adsorption efficiency for nickel ion removal from an aqueous solution.

\section{Introduction}

Environmental pollution by the presence of heavy metals has aroused enormous attention of researchers because of their toxicity, harmfulness, and nondegradability in the ecosystem [1-3]. Metal-containing effluents from different activities (e.g., domestic, industrial, and agriculture) pollute the aqueous environment (both surface and underground water) continuously. Heavy metals are considered to be significantly dangerous to mankind because of their hazardous nature [4]. Mining, jewelry, Cd-Ni battery, alloy, metallurgical, and metal plating industries are stated to be the major source of metal-containing waste pollution $[5,6]$. Nickel concentrations in air are typically $0.00001-0.003 \mu \mathrm{g} /$ $\mathrm{m}^{3}$ in remote places, $0.003-0.03 \mu \mathrm{g} / \mathrm{m}^{3}$ in municipal and metropolitan places, and $0.07-0.77 \mu \mathrm{g} / \mathrm{m}^{3}$ in nickel processing industries as well as in similar manufacturing plants [7]. According to the World Health Organization (WHO, the year 2020), the nickel concentration in drinking water is $2-13 \mu \mathrm{g} / \mathrm{L}$ in European countries.
Nickel (Ni) is found in several minerals formed in nature. For example, in the earth's crust, nickel is the $24^{\text {th }}$ most abundant natural element that covers about $3 \%$ of the earth's composition [7]. In the periodic table, nickel stands in group VIII B along with other transition metal elements such as iron, cobalt, palladium, and platinum. Being a toxic metal, nickel poses serious concern due to its carcinogenic potency to human beings. Nickel causes various diseases such as cardiac arrest, respiratory problems, kidney damage, and gastrointestinal distress [8]. Therefore, along with other metals such as $\mathrm{Cd}, \mathrm{Zn}$, and $\mathrm{Pd}$, it is necessary to remove $\mathrm{Ni}$ ions from wastewater of industrial establishments before their discharge to the water reservoirs as well as to the environment [9]. However, still, an efficient and cost-effective method of Ni ions removal from industrial wastewater remains a challenge.

Since nickel contamination is a global environmental problem, several research works have been conducted to develop improved as well as effective treatment technologies for the removal of nickel along with harmful metal ions from 
wastewater. Technologies to remove metal ions are solvent extraction, electrochemical precipitation, membrane filtration, ion-exchange process, reverse osmosis method, photocatalytic reduction, adsorption [10-13], etc. Despite such varieties of nickel removal technologies, none of them alone is cheap, easy to operate, and environmentally friendly. For example, the precipitation-coagulation method is simple in operation; however, it produces a large amount of sludge that must be treated afterward and leads to high disposal costs. Anion-exchange processes have a quite low selectivity in the dynamic presence of other competing metal ions $[14,15]$. Reverse osmosis and ion exchange, although efficient, are expensive due to high operational and maintenance costs throughout their working life.

Adsorptive removal is a simple process, which can be cheap and environmentally benign depending on the nature of adsorbents. Therefore, in recent years, a trend toward using low-cost and readily available waste materials as biosorbents for the removal of heavy metals from wastewater is observed. A number of waste materials-based biosorbents such as coconut husk, wheat and barley straw [16], blood banana [13], orange waste [14], waste paper [17], nutshells [18], and sawdust $[2,19,20]$ have been exploited for the removal of metal ions from aquatic media. Among the low-cost biosorbents, sawdust is a promising one, which can be effectively used for dye removal after treatment with formaldehyde $[21,22]$. Even though various types of sawdust have been used as biosorbents, to the best of our knowledge, studies on the use of locally obtained mahogany (Swietenia macrophylla) sawdust as well as other types of sawdust for nickel removal from aqueous solutions are not available. Mahogany is a common tree in Bangladesh and is widely used in furniture making. In this investigation, mahogany sawdust was chemically treated and used as a biosorbent for the removal of nickel ions $\left(\mathrm{Ni}^{2+}\right)$ from an aqueous solution. The effects of various parameters such as solution $\mathrm{pH}$, adsorbent dosage, contact time, metal concentration, and temperature on the removal of $\mathrm{Ni}$ (II) were studied through different sets of batch experiments. The adsorption isotherm, kinetics, mechanism, and various thermodynamic parameters have also been presented.

\section{Materials and Methods}

2.1. Chemicals. Nickel chloride $\left(\mathrm{NiCl}_{2}\right)$ was dissolved in distilled water to prepare a synthetic stock solution of nickel $(1000 \mathrm{mg} / \mathrm{L})$, which was diluted as necessary to prepare a working solution while conducting batch adsorption experiments. As-received formaldehyde $(\mathrm{H}-\mathrm{CHO})$ was used to prepare $2 \%$ of its solution. However, to adjust the $\mathrm{pH}$ of the working solutions, hydrochloric acid $(0.1 \mathrm{M} \mathrm{HCl})$ and sodium hydroxide $(0.1 \mathrm{M} \mathrm{NaOH})$ solutions were used throughout the investigation. All the reagents and chemicals (Merck, Germany) used in this work were of analytical reagent grade and purchased from the local supplier.

\subsection{Preparation of Chemically Treated Mahogany Sawdust as} Biosorbent. Mahogany (Swietenia macrophylla) sawdust was collected from a sawmill located in the suburban area of
Jashore, Bangladesh. The sawdust was first washed with distilled water to eliminate dust and other unwanted particles. It was then dried in a convection dryer at $70^{\circ} \mathrm{C}$ until all the moisture from the sawdust was completely evaporated. The sawdust was ground to make a fine powder using a mortar and pestle [3]. The powdered material obtained after grinding was sieved to obtain a particle size range of $100-150 \mu \mathrm{m}$. For chemical treatment of the sawdust powder, $2 \%$ formaldehyde was mixed with powdered sawdust at a ratio of $4: 1$ (formaldehyde : sawdust, $\mathrm{v} / \mathrm{w}$ ) to immobilize the water-soluble substances and color at room temperature by shaking for three hours. After that treatment, the sawdust was filtered and washed with distilled water to remove free formaldehyde (not bonded with the surface), and it was dried in a convection dryer (HDG-9030, Korea) at $70^{\circ} \mathrm{C}$ for 24 hours. The obtained material was kept in an air-tight container for further use.

2.3. Characterizations. Fourier transform infrared spectroscopy (IRTracer-100, Shimadzu, Japan) was analyzed to comprehend the major contributing functional groups of the biosorbent that might take part in metal adsorption. FTIR spectra of the biosorbent before and after nickel ions adsorption were performed so that the involvement of functional groups becomes clear. The surface morphology of the biosorbent in both cases (before and after nickel ions adsorption) was studied with a field emission scanning electron microscope (FESEM, JSM 7600F, JEOL Inc., Japan) at a working voltage of $5 \mathrm{kV}$ with different magnifications.

2.4. Batch Adsorption Experiments. Batch adsorption tests were carried out by taking $1000 \mathrm{mg}$ of the treated sawdust in an Erlenmeyer flask in which $100 \mathrm{ml}$ of adsorbate (nickel) solution was taken at the required concentration. The entire suspension was then shaken at $200 \mathrm{rpm}$ in a magnetic stirrer (MS300HS, Korea). After a certain time, the suspension was filtered using filter paper. The liquid fraction was then used to analyze the amount of nickel ion using atomic absorption spectrophotometer (AA-7000, Shimadzu, Japan). It is important to note that either $0.1 \mathrm{M}$ $\mathrm{HCl}$ or $0.1 \mathrm{M} \mathrm{NaOH}$ solution was added to the solution to keep a constant $\mathrm{pH}$ of the solution to avoid nickel precipitation. The $\mathrm{pH}$ of the solution was measured by a portable $\mathrm{pH}$ meter (EZODO 6011, Taiwan). In general, batch adsorption tests were carried out to study the impact of $\mathrm{pH}$ of the initial nickel solution at $\mathrm{pH}$ ranging from 4 to 10.5 , amount of adsorbent dosage of $200-1800 \mathrm{mg}$, contact time of $0-360 \mathrm{~min}$, initial nickel ion concentrations of $10-500 \mathrm{mg} / \mathrm{L}$ in the mother solution, and sorption temperature of $298-318 \mathrm{~K}$. All the experiments were performed at room temperature unless otherwise stated. To avoid experimental errors, all the investigations were replicated three times. The average value of these three was taken for further data interpretation and graph plotting.

The total nickel ion adsorption percentage was calculated using the following equation: 


$$
\% \text { adsorption }=\left\{\frac{\left(C_{i n}-C_{e q}\right)}{C_{i n}}\right\} \times 100,
$$

where $C_{i n}$ and $C_{e q}$ are the initial and equilibrium nickel ion concentration $(\mathrm{mg} / \mathrm{L})$ in the solution, respectively.

In addition, the adsorption capacity $(q)$ for any single experiment was calculated using the following equation:

$$
q=\frac{\left\{\left(C_{i n}-C_{e q}\right) \times V\right\}}{M},
$$

where $q$ is the amount of nickel adsorbed $(\mathrm{mg} / \mathrm{g}), V$ is the volume of the liquid solution (L), and $M$ is the amount of the powdered sawdust biosorbent (g).

\section{Results and Discussion}

3.1. Characterization of the Biosorbent. The structure of the adsorbent is important to know the morphology of the biosorbent and to understand the adsorption process. The cell walls of sawdust mainly consist of cellulose, hemicellulose, lignin, tannins, etc., which contain a considerable amount of hydroxyl groups [23]. All these components are active ion-exchange compounds since they contain different functional groups. Being a polymeric material, the lignin molecule is made up of the phenylpropane nucleus, an aromatic ring having three-carbon side chains, which are readily available to interact with cationic metal ions $[2,23]$.

\subsubsection{Fourier Transform Infrared (FTIR) Spectroscopy.}

Sawdust contains cellulose, hemicellulose, lignin, pectin, and other extractives such as waxes. Metal ions are supposed to be adsorbed to carboxylic (present in hemicellulose, pectin, and lignin), phenolic (present in lignin), hydroxyl (present in cellulose, hemicellulose, lignin, and pectin), and carbonyl groups (lignin and pectin). The FTIR spectrum of sawdust biosorbent exhibited numerous absorption peaks (Supplementary Figure S1), which indicated the complex nature and heterogeneity of this material [23]. The assignment of each peak at a specific wavenumber for sawdust (before and after adsorption) is listed in Table 1. The peaks, which correspond to different functional groups, are the possible adsorption sites. The functional groups present in the sawdust biosorbent may donate protons, and thus deprotonated groups are created at the surface of the biosorbent. These deprotonated groups may be involved in coordination with nickel ions resulting in adsorption of the metal ions [23].

As seen from Table 1, many wavenumbers are found to slightly deviate (both position and intensity) after nickel ion adsorption, which may be attributed to the shift of some functional group's band during the process of adsorption. These shifts may occur because of changes in counterions associated with carboxylate and hydroxylate anions. The deviation of wavenumbers demonstrates that a metalbinding process took place at the biosorbent surface [24]. The similarity of spectra between the biosorbent without metal adsorption and after metal adsorption indicates that the adsorption of nickel ions on the surface of the biosorbent
TABLE 1: The FTIR spectral characteristics of sawdust before and after adsorption of nickel ions.

\begin{tabular}{lccc}
\hline $\begin{array}{l}\text { Before } \\
\text { adsorption }\end{array}$ & $\begin{array}{c}\text { Wavenumber }\left(\mathrm{cm}^{-1}\right) \\
\text { After } \\
\text { adsorption }\end{array}$ & Differences & Assignments \\
\hline 3437 & 3410 & -27 & O-H stretching \\
2924 & 2916 & -8 & C-H stretching \\
1737 & 1737 & 0 & C-H bending \\
1635 & 1631 & -4 & C=C stretching \\
1510 & 1504 & -6 & N-O stretching \\
1462 & 1462 & 0 & C-H bending \\
1423 & 1425 & +2 & O-H bending \\
1373 & 1375 & +2 & O-H bending \\
1321 & 1330 & +9 & S=O stretching \\
1247 & 1247 & 0 & C-O stretching \\
1161 & 1161 & 0 & C-O stretching \\
1120 & Nil & Absent & C-O stretching \\
1056 & 1056 & 0 & S=O stretching \\
900 & 898 & -2 & C-H bending \\
\hline
\end{tabular}

was accomplished either through complexation or through physical processes that include both weak electrostatic interaction and Van der Waals force [2].

3.1.2. Scanning Electron Microscopy (SEM) Analysis and Energy Dispersive X-Ray (EDX) Spectroscopy. The morphological properties (surface texture and porosity) of treated mahogany sawdust before and after nickel adsorption were investigated using SEM, which is depicted in Figure 1. In the case of fresh treated sawdust (before adsorption), the figure shows the interior microstructure of the biosorbent, which confirms a well-defined porous structure. Moreover, the sawdust (before metal adsorption) contains a rough surface with many tunnel-like structures, and the porous structure slightly decreased after the adsorption of nickel ions. The EDX spectroscopy clearly shows that after the adsorption process nickel is adsorbed onto the treated sawdust. From EDX analysis, the nickel content was found to increase by $0.98 \%$, which indicated successful adsorption of nickel on treated sawdust. A lesser nickel content (0.09\%) was reported to be adsorbed using dried biomass (named Ulva lactuca) from an aqueous solution [25].

3.2. Effect of Solution $p H$. The $\mathrm{pH}$ of the working solution is one of the important parameters that influence metal ion adsorption. The $\mathrm{pH}$ of the solution influences the dissociation of functional groups as well as solution chemistry, and thus it has a significant effect on biosorption capacity [26]. Moreover, the $\mathrm{pH}$ affects the metal ion chemistry (such as degree of ionization and state) in the solution as well as the stability of different metal ion species in the solution $[3,27]$. In the present study, the effect of change in solution $\mathrm{pH}$ on the removal of $\mathrm{Ni}$ (II) was studied by varying the $\mathrm{pH}$ of the solution from 4 to 10.5 at a fixed $\mathrm{Ni}$ (II) initial concentration of $25 \mathrm{mg} / \mathrm{L}$. As depicted in Figure 2, the adsorptive removal of nickel significantly depends on $\mathrm{pH}$. Nickel removal percentage increases with the increase in solution $\mathrm{pH}$, and 

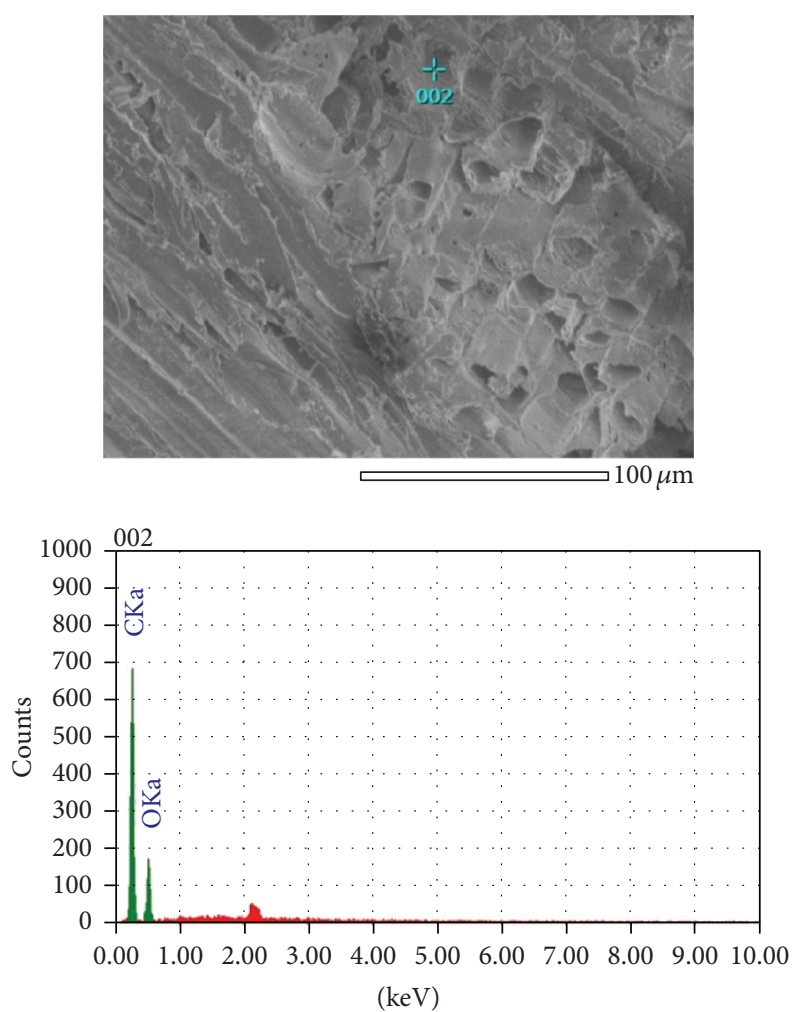

(a)
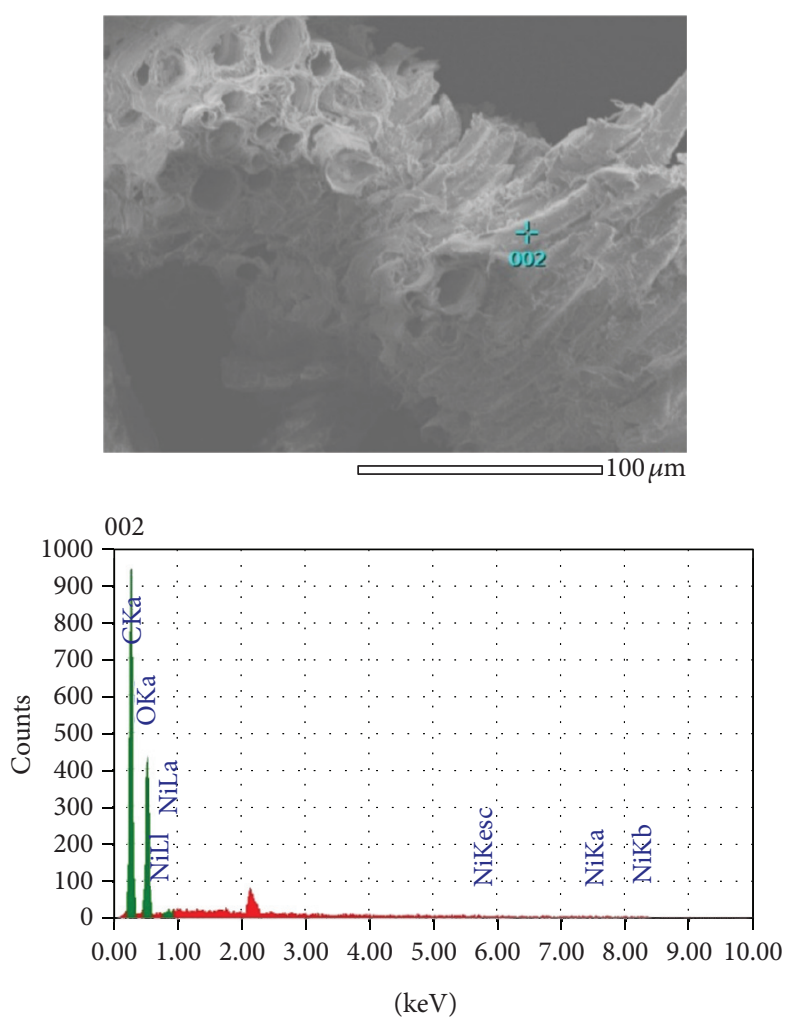

(b)

FIGURE 1: SEM-EDX images and spectra of treated sawdust (a) before and (b) after adsorption of nickel ions.

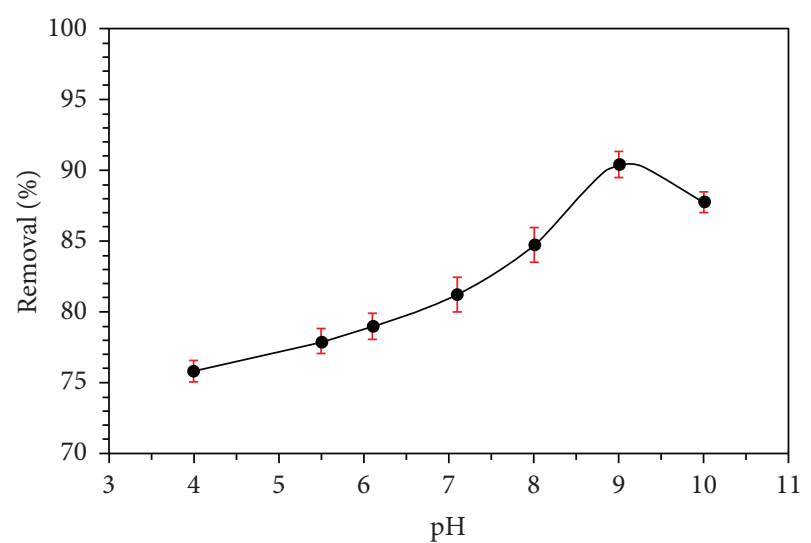

Figure 2: Effect of $\mathrm{pH}$ on the removal of $\mathrm{Ni}$ (II) using sawdust. Condition: $T=298 \mathrm{~K}, t=6 \mathrm{~h}$, and dose $=15 \mathrm{mg} / \mathrm{ml}$.

maximum adsorption was found to occur at $\mathrm{pH} 9$ (at the stated conditions). The point of zero charge $\left(\mathrm{pH}_{\mathrm{pzc}}\right)$ of the adsorbent was determined too, and the extent of $\mathrm{pH}_{\mathrm{pzc}}$ was found to be 6.8 (as shown in Supplementary Figure S2). Cation adsorption used to improve at $\mathrm{pH}$ higher than $\mathrm{pH}_{\mathrm{pzc}}$. The experimental results (Figure 2) show a similar trend as the nickel removal increases significantly after $\mathrm{pH} 6.8$. Depending on the $\mathrm{pH}$ of the solution, nickel exists mainly as four different species with different coordination numbers such as $\mathrm{Ni}^{2+}, \mathrm{Ni}(\mathrm{OH})^{+}, \mathrm{Ni}(\mathrm{OH})_{2}$, and $\mathrm{Ni}(\mathrm{OH})_{3}^{-}$. From the speciation diagram, as reported by Gonsalvesh et al., it is obvious that up to $\mathrm{pH} 9$ the predominant nickel species is $\mathrm{Ni}^{2+}$ [27]. Therefore, it is comprehended that cation exchange, as well as direct surface complexation, might play a vital role in removing (through adsorption) metal ions in this case [28].

One thing to note here is that as the $\mathrm{pH}$ of the stock solution was increased above $\mathrm{pH} 9$, the percentage removal of nickel decreased. This phenomenon can be elucidated with the fact that soluble hydroxyl complexes formed at higher $\mathrm{pH}$ and, thus, the sorption mechanism changes. A similar explanation has been reported for various metal ions adsorption by biosorbents [2, 25].

3.3. Effect of Biosorbent Dosage. To find out a perfect biosorbent dose, batchwise adsorption studies of Ni (II) ions onto the treated mahogany (Swietenia macrophylla) sawdust were carried out at $30^{\circ} \mathrm{C}$ where the dose was varied from $2 \mathrm{~g} /$ $\mathrm{L}$ to $18 \mathrm{~g} / \mathrm{L}$ keeping the solution $\mathrm{pH}$ constant. The percentage of nickel adsorption on sawdust concerning the adsorbent dosage is shown in Figure 3. The figure shows that as the adsorbent dosage increases (from $2 \mathrm{~g} / \mathrm{L}$ to $15 \mathrm{~g} / \mathrm{L}$ ), the total adsorption percentage increases gradually (from $41 \%$ to $85 \%)$. However, the adsorption percentage remains almost constant despite a further increase in adsorbent dosage (i.e., higher than $15 \mathrm{~g} / \mathrm{L}$ ). The observed tendency can be explained by the fact that the total surface area of the adsorbent and the number of active sorption sites increase with the increase of adsorbent quantity. A similar phenomenon has been 


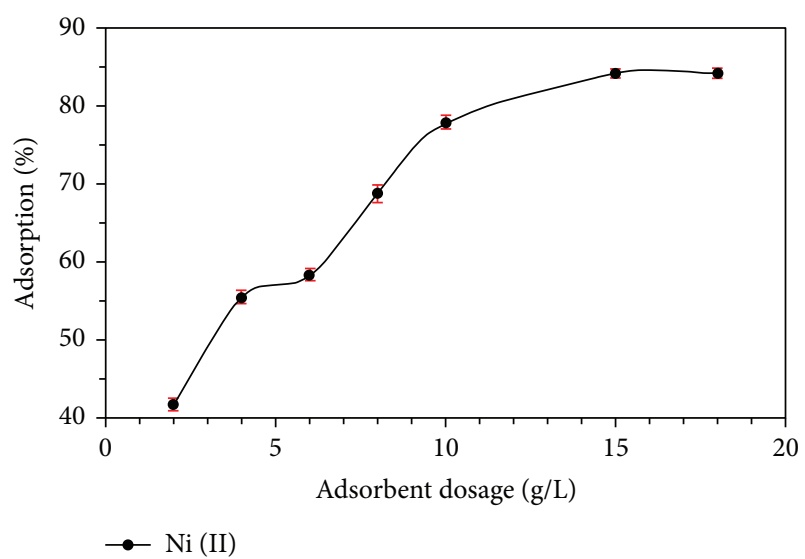

Figure 3: Effect of amount of adsorbent on the removal of nickel using treated sawdust. Condition: $T=303 \mathrm{~K}$ and $t=6 \mathrm{~h}$.

reported in the literature for nickel adsorption onto sawdust and/or sawdust-derived biosorbents [1,3]. Taking these results into consideration, an adsorbent dosage of $15 \mathrm{~g} / \mathrm{L}$ was chosen for further adsorption studies.

3.4. Effect of Contact Time. To select the required time for the equilibrium to be attained, preliminary experiments were conducted at initial $\mathrm{Ni}$ (II) concentrations of $40 \mathrm{mg} / \mathrm{L}$ and $50 \mathrm{mg} / \mathrm{L}$ in the solution, and the result is presented in Figure 4. As seen from this figure, the amount of adsorbed $\mathrm{Ni}^{2+}$ ions increased with increasing time. It is obvious that a significant separation of $\mathrm{Ni}$ (II) ions occurred within $120 \mathrm{~min}$ under $200 \mathrm{rpm}$ stirring, and in the later stage, the adsorption capacity became invariable. A similar result has been reported for the removal of $\mathrm{Cu}$ (II), $\mathrm{Pb}$ (II), and $\mathrm{Cd}$ (II) ions from an aqueous solution by inexpensive biopolymeric sorbent [29]. However, to ensure complete adsorption, all other experiments were allowed to run for $6 \mathrm{~h}$ at the given conditions. The initial high rate of percentage uptake of $\mathrm{Ni}^{2+}$ ions is perhaps due to the availability of a larger surface area of the biosorbent which gives free adsorption sites of treated mahogany sawdust. Nickel ions are transported firstly from the bulk solution to the outer biosorbent surface and then from the outer surface to the inner surface of the pores. Thus, with time the surface adsorption sites (outer as well as inner) become gradually occupied. However, the rate of adsorption is thought to be controlled by the transport rate of metal ions from the exterior to the interior sites (through pores) of the biosorbent.

3.5. Kinetic Studies of Nickel Ions Adsorption. The rate of adsorptive interaction onto the sawdust was estimated using the linearized integral form of Lagergren's pseudo-firstorder and pseudo-second-order kinetic models [30]. The respective model equations are given as follows:

$$
\begin{aligned}
\log \left(q_{e}-q_{t}\right) & =\log q_{e}-\frac{k_{1} t}{2.303} \\
\frac{t}{q_{t}} & =\frac{1}{k_{2} q_{e}^{2}}+\frac{t}{q_{e}}
\end{aligned}
$$

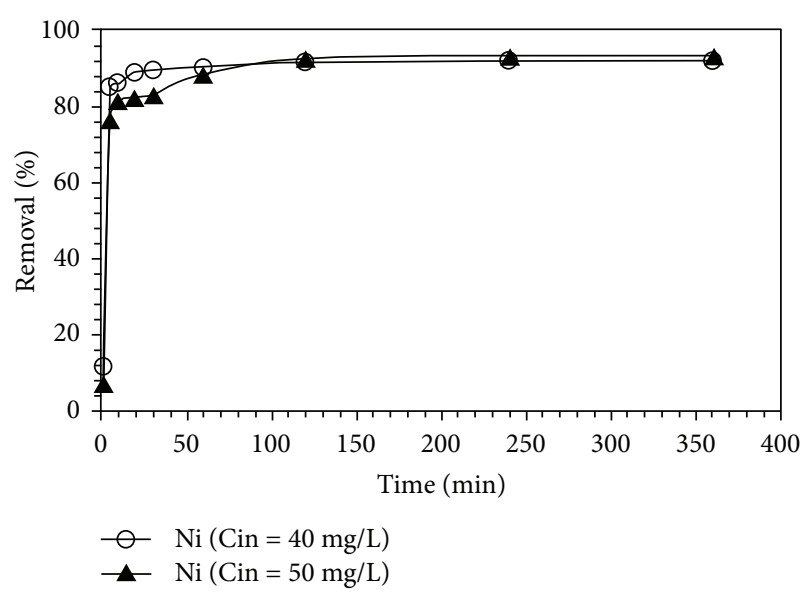

FIgURe 4: Percent removal of nickel with respect to time at different initial nickel concentrations.

where $q_{e}(\mathrm{mg} / \mathrm{g})$ and $q_{t}(\mathrm{mg} / \mathrm{g})$ are the amount of nickel adsorbed onto the sawdust biosorbent at equilibrium and the amount of nickel adsorbed at time $t(\mathrm{~min})$, respectively; $k_{1}$ $(1 / \mathrm{min})$ is the first-order adsorption rate constant; and $k_{2}(\mathrm{~g} /$ (mg.min)) is the second-order adsorption rate constant.

To determine the adsorption kinetics, both pseudofirst-order and pseudo-second-order models were tested and are shown in Figure 5. The conformity between the experimental data and the predicted values from the model was expressed by correlation coefficient $\left(R^{2}\right)$. The pseudo-second-order model is the best-suited because its $R^{2}$ values $(0.9998$ and 0.9982 for $40 \mathrm{mg} / \mathrm{L}$ and $50 \mathrm{mg} / \mathrm{L}$, respectively) were near to conformity compared to the $R^{2}$ values $(0.8119$ and 0.9582 for $40 \mathrm{mg} / \mathrm{L}$ and $50 \mathrm{mg} / \mathrm{L}$, respectively) of the pseudo-first-order kinetic model. Moreover, calculated values (from (4)) of amounts adsorbed exhibited excellent agreement with the values obtained from experiments $\left(q_{\text {exp }}\right)$. Similar results have been reported for the adsorption of metal ions with other types of dried biomass [25, 31]. Both experimental and calculated values of rate constants, correlation coefficients, and amounts adsorbed are tabulated in Table 2.

In general, for well-stirred batch-mode adsorption experiments, transport of absorbate from the bulk solution to the adsorbent pores may be considered as the rate-controlling step [32]. Such postulation can be generally studied by applying Webber-Morris intraparticle diffusion model [33]. Thus, for comprehending the adsorption mechanism of nickel on mahogany sawdust, the kinetic data were further analyzed using the Webber-Morris intraparticle diffusion model, and the related equation is expressed as follows:

$$
q_{t}=k_{i d} t^{1 / 2}+C
$$

where $q_{t}(\mathrm{mg} / \mathrm{g})$ is the adsorption capacity at time $t$, while $k_{i d}$ (g/(mg.min $\left.\left.{ }^{-0.5}\right)\right)$ and $C$ are intraparticle diffusion rate constant and boundary layer thickness, respectively. By plotting $q_{t}$ vs $t^{1 / 2}$, the parameters (i.e., $k_{i d}$ and $C$ ) were then calculated from the slope and intercept of the linear plot, respectively (shown in Figure 6). It is evident from Figure 6 that there are two separate regions in each of the plotted 


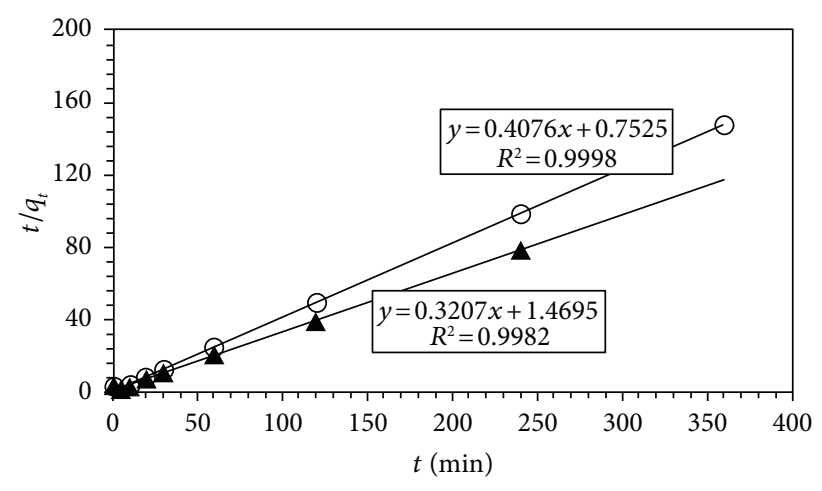

O $\mathrm{Ni}(\mathrm{Cin}=40 \mathrm{mg} / \mathrm{L})$

\ $\mathrm{Ni}(\mathrm{Cin}=50 \mathrm{mg} / \mathrm{L})$

Figure 5: Pseudo-second-order kinetic plot for the adsorption of nickel at $303 \mathrm{~K}$.

TAble 2: Pseudo-first-order and pseudo-second-order kinetic models for the adsorption of Ni(II) on mahogany sawdust.

\begin{tabular}{lcccccc}
\hline \multirow{2}{*}{ Metal $(\mathrm{mg} / \mathrm{L})$} & $q_{\exp }(\mathrm{mg} / \mathrm{g})$ & $q_{e}(\mathrm{mg} / \mathrm{g})$ & $k_{1}(1 / \mathrm{min})$ & $R^{2}$ & $q_{e}(\mathrm{mg} / \mathrm{g})$ & $\begin{array}{c}\text { Pseudo-second-order } \\
k_{2}(\mathrm{~g} /(\mathrm{mg} \cdot \mathrm{min}))\end{array}$ \\
\hline 40 & 2.44 & 0.20 & 0.0073 & 0.8119 & 2.45 & 0.2208 \\
50 & 3.05 & 0.89 & 0.0132 & 0.9582 & 3.11 & 0.9998 \\
\hline
\end{tabular}

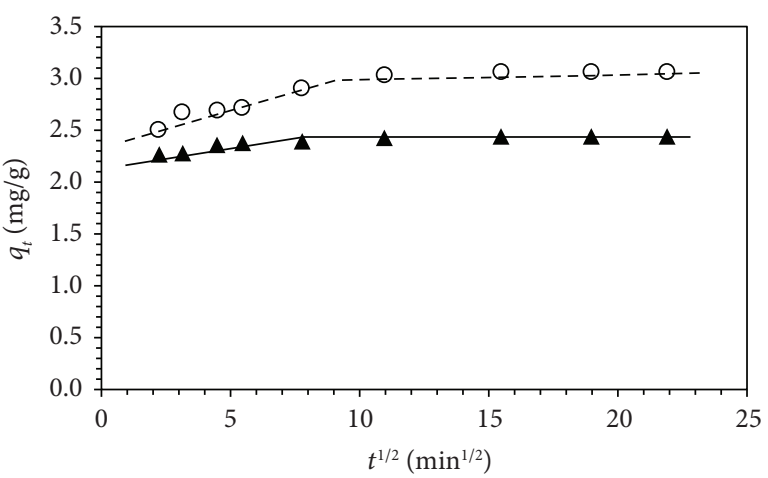

A $40 \mathrm{mg} / \mathrm{L}$

○ $50 \mathrm{mg} / \mathrm{L}$

FIgURE 6: Weber-Morris plot for nickel ion adsorption.

lines, which is an indication of multistage adsorption of nickel on mahogany sawdust. The first linear region was the instantaneous adsorption or external surface adsorption stage, while the second linear region represented the intraparticle diffusion or pore diffusion stage. The intraparticle diffusion rates $\left(k_{i d}\right)$ for the first and second linear stages were calculated to be $0.0263 \mathrm{~g} /\left(\mathrm{mg} \cdot \mathrm{min}^{-0.5}\right)$ and $0.0008 \mathrm{~g} /\left(\mathrm{mg} \cdot \mathrm{min}^{-0.5}\right)$, respectively (for the initial nickel concentration of $40 \mathrm{mg} / \mathrm{L}$ ). Similarly, $k_{i d}$ in case of the initial nickel concentration of $50 \mathrm{mg} / \mathrm{L}$ was determined as $0.0626 \mathrm{~g} /$ (mg. $\mathrm{min}^{-0.5}$ ) and $0.0019 \mathrm{~g} /\left(\mathrm{mg} \cdot \mathrm{min}^{-0.5}\right)$ for the first linear portion and second linear portion, respectively.

3.6. Adsorption Isotherm Studies. The relationship between the concentration of the adsorbate and its extent of adsorption onto the adsorbent surface at a fixed temperature can be well described by adsorption isotherms. In the present investigation, Langmuir, Freundlich, and Dubinin-Radushkevich (D-R) isotherm models were used to quantify the adsorption capacity of mahogany sawdust for the removal of $\mathrm{Ni}$ (II) from aqueous solution. The adsorption isotherm studies were conducted using an initial nickel concentration range of $10-500 \mathrm{mg} / \mathrm{L}$ and at an operating sorption temperature range of $298-318 \mathrm{~K}$.

3.6.1. Langmuir Model. The Langmuir isotherm model is developed on the assumption that the adsorption takes place on specific homogeneous sites by monolayer adsorption process, which signifies that once an adsorbate occupies a vacant adsorption site, then no further adsorption takes place on that site. However, the Langmuir isotherm model can be defined by the following equation $[25,33]$ :

$$
\frac{C_{e}}{q_{e}}=\frac{C_{e}}{q_{\max }}+\frac{1}{b q_{\max }},
$$

where $C_{e}(\mathrm{mg} / \mathrm{L})$ is the equilibrium concentration of nickel, $q_{e}(\mathrm{mg} / \mathrm{g})$ is the amount of nickel adsorbed at equilibrium, $q_{\max }(\mathrm{mg} / \mathrm{g})$ is the maximum adsorption capacity, and $b$ (L/ $\mathrm{mg}$ ) is the equilibrium constant. Hence, a straight line is obtained by plotting $C_{e} / q_{e}$ vs $C_{e}$ for three different temperatures. Values of $q_{\max }$ and $b$ can be obtained, respectively, from the slope and intercept of the straight lines of the figure. However, the calculated values are presented in Table 3.

3.6.2. Freundlich Model. Another isotherm model tested in this study was the Freundlich isotherm model, which is supposed to deal with the multilayer adsorption of adsorbate (nickel ions) on the biosorbent (sawdust). The model can be applied for a nonideal sorption process where heterogeneous 
TABLE 3: Isotherm constants and correlation coefficients for the adsorption of nickel on sawdust.

\begin{tabular}{lcccc}
\hline \multirow{2}{*}{ Isotherms } & Parameters & \multicolumn{3}{c}{$T(\mathrm{~K})$} \\
& & 298 & 308 & 318 \\
\hline \multirow{3}{*}{ Langmuir } & $q_{\max }(\mathrm{mg} / \mathrm{g})$ & 13.42 & 14.03 & 14.43 \\
& $b(\mathrm{~L} / \mathrm{mg})$ & 0.031 & 0.029 & 0.024 \\
& $R^{2}$ & 0.9856 & 0.9904 & 0.9835 \\
\hline \multirow{4}{*}{ Freundlich } & $1 / n$ & 0.568 & 0.554 & 0.558 \\
& $K_{f}$ & 0.696 & 0.720 & 0.704 \\
& $R^{2}$ & 0.9740 & 0.9256 & 0.9596 \\
\hline \multirow{5}{*}{ Dubinin-Radushkevich } & $K_{a d}\left(\mathrm{~mol}^{2} / \mathrm{kJ}^{2}\right)$ & 0.1732 & 0.2006 & 0.165 \\
& $q_{s}\left(\mathrm{mg}^{\prime} / \mathrm{g}\right)$ & 22.43 & 27.36 & 19.70 \\
& $E\left(\mathrm{~kJ} / \mathrm{mol}^{2}\right)$ & 1.699 & 1.579 & 1.741 \\
& $R^{2}$ & 0.9016 & 0.9031 & 0.7948 \\
\hline
\end{tabular}

sites are in effect. The isotherm is commonly expressed as follows [24]:

$$
\log q_{e}=\log K_{f}+\frac{1}{n} \log C_{e},
$$

where $q_{e}(\mathrm{mg} / \mathrm{g})$ and $C_{e}(\mathrm{mg} / \mathrm{L})$ are symbolized as adsorption capacity and adsorbate concentration at equilibrium, respectively; $K_{f}$ is the Freundlich constant that indicates a relationship between the adsorption capacity and bonding energy; and $1 / n$ is designated as the Freundlich coefficient that represents the factor of heterogeneity as follows [24]. The values of $K_{f}$ and $1 / n$ for different temperatures (for example, $298 \mathrm{~K}, 308 \mathrm{~K}$, and $318 \mathrm{~K}$ in this study) can be obtained from the intercepts and the slopes of linear plots of $\log q_{e}$ vs $\log C_{e}$. The related parameters of the Freundlich isotherm model were calculated and the values are presented in Table 3 .

3.6.3. Dubinin-Radushkevich (D-R) Model. The D-R isotherm model is an empirical adsorption model based on the consideration of multilayer character involving Van der Waals force, which is related to the physical adsorption process on heterogeneous surfaces. The model also presumes the adsorption on the microporous adsorbent and is applied for distinguishing between chemical and physical sorption processes. The model is expressed as follows:

$$
\ln q_{e}=\ln q_{s}-K_{a d} \varepsilon^{2},
$$

where $q_{e}(\mathrm{mg} / \mathrm{g})$ is the amount of adsorbate in the adsorbent at equilibrium, $q_{s}(\mathrm{mg} / \mathrm{g})$ is the theoretical isotherm saturation capacity, $K_{a d}\left(\mathrm{~mol}^{2} / \mathrm{kJ}^{2}\right)$ is the activity coefficient related to the mean free energy or often called D-R constant, and $\varepsilon$ is the Polanyi potential. The term Polanyi potential $(\varepsilon)$ is expressed as follows [34]:

$$
\varepsilon=R T\left(1+1 / C_{e}\right),
$$

where $R(\mathrm{~J} /(\mathrm{mol} \cdot \mathrm{K})), T(\mathrm{~K})$, and $C_{e}(\mathrm{mg} / \mathrm{L})$ signify gas constant, absolute temperature, and adsorbate concentration at equilibrium, respectively. From the resulting linear plot of $\ln q_{e}$ vs $\varepsilon^{2}$, the values of $q_{s}$ and $K_{a d}$ are determined from the intercept and slope, respectively (values are given in Table 3$)$. However, the mean adsorption energy $(E, \mathrm{~kJ} / \mathrm{mol})$ is a characteristic parameter, which defines the chemical or physical nature of the adsorption reaction. The value of $E$ is calculated from the following equation:

$$
E=\frac{1}{\sqrt{2 K_{a d}}}
$$

The necessary parameters $\left(E\right.$ and $\left.K_{a d}\right)$ derived from the $\mathrm{D}-\mathrm{R}$ isotherm model are tabulated in Table 3 along with the parameters obtained from Langmuir as well as Freundlich isotherm models. Results showed that the Langmuir isotherm model had a higher coefficient of determination $\left(R^{2}\right)$ for all tested temperatures. This leads to the conclusion that the Langmuir model described the entire adsorption method better than the Dubinin-Radushkevich and Freundlich models. It is also evident that an elevated temperature was more favorable for the adsorption of nickel at the stated conditions. This indicates that the adsorption process is endothermic. The calculated $E$ values from the D-R model are in the range of $1.5-1.8 \mathrm{~kJ} / \mathrm{mol}$, so it is physical adsorption [35].

Moreover, the adsorption capacity for the removal of nickel ions of the present biosorbent has been compared with that of several other biosorbents published in the literature, and the values of adsorption capacities are presented in Table 4. The extent of the sorption capacity of the present investigation is considerably high and very much comparable with the reported values.

Further analysis of the Langmuir isotherm was carried out to determine a dimensionless constant, which is known as the equilibrium parameter or separation factor $\left(R_{L}\right)$ [41]. It indicates the favorability of the isotherm, and the separation factor is expressed as follows:

$$
R_{L}=\frac{1}{1+b C_{i}},
$$

where $b(\mathrm{~L} / \mathrm{mg})$ and $C_{i}(\mathrm{mg} / \mathrm{L})$ are the equilibrium constant and the initial concentration of the adsorbate. Here, if the value of $R_{L}$ stands between 0 and 1 , this means the adsorption is favorable, and if $R_{L}$ is greater than $1\left(R_{L}>1\right)$, this means the adsorption is unfavorable. In addition, $R_{L}=1$ signifies a linear adsorption while $R_{L}=0$ denotes an irreversible adsorption process [42]. Figure 7 shows a plot of $R_{L}$ vs $C_{i}$, from which it is obvious that the $R_{L}$ values remained between 0.061 and 0.823 . Therefore, the adsorption of nickel by sawdust was termed as favorable at the studied conditions.

Safe disposal of biosorbent after adsorption of the metal ion is an issue to be considered very carefully. Although the cost estimation is not performed in the present study, it is envisaged that the disposal cost might be offset from the overall cost of the biosorption process because the spent biosorbent might be applied in other fields such as the production of building materials (e.g., cement), particle boards, and biogas [43].

3.7. Effect of Sorption Temperature and Subsequent Thermodynamic Study. The adsorption capacity of mahogany sawdust for nickel ions adsorption increases with the 
TABLE 4: Comparison of adsorption capacities of different water material-based adsorbents for nickel ion adsorption.

\begin{tabular}{lcc}
\hline Adsorbent material & Adsorption capacity $(\mathrm{mg} / \mathrm{g})$ & References \\
\hline Treated mahogany sawdust & 13.42 & This investigation \\
Raw mahogany sawdust & 5.35 & This investigation \\
Banana peel & 6.88 & {$[36]$} \\
Orange peel & 6.01 & {$[36]$} \\
Pine sawdust & 0.065 & {$[37]$} \\
Rice husk & $0.21-7.63$ & {$[38]$} \\
Aluminum impregnated fly ash & 12.67 & {$[39]$} \\
Coconut coir pith & 24.39 & {$[40]$} \\
Activated carbon/chitosan bead & 108.7 & {$[39]$} \\
\hline
\end{tabular}

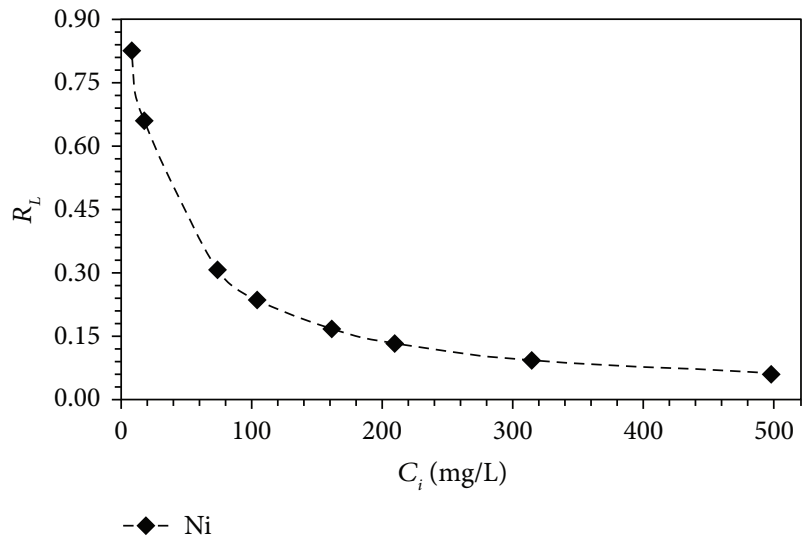

FIgURE 7: Separation factor of nickel adsorption by sawdust.

increase of sorption temperature. This trend might be explained by a chemical interaction between adsorbate and adsorbent through the movement of the adsorbing nickel ion species and/or enlargement of the pore size. These phenomena eventually enhance the rate of intraparticle diffusion of $\mathrm{Ni}$ (II) into the biosorbent pores [20].

Moreover, to assess the effect of temperature on the adsorption of $\mathrm{Ni}$ (II) onto mahogany sawdust, important thermodynamic parameters, which include standard Gibb's free energy $\left(\Delta G^{\circ}\right)$, standard enthalpy change $\left(\Delta H^{\circ}\right)$, and standard entropy change $\left(\Delta S^{\circ}\right)$, were calculated using the following two thermodynamic equations $[3,25]$ :

$$
\begin{gathered}
\Delta G^{0}=-R T \ln b, \\
\ln b=\frac{\Delta S^{0}}{R}+\frac{\Delta H^{0}}{R T},
\end{gathered}
$$

where $R(\mathrm{~J} /(\mathrm{mol} \cdot \mathrm{K}))$ represents the ideal gas constant and $T(\mathrm{~K})$ and $b(\mathrm{~L} / \mathrm{mg})$ represent the absolute temperature and equilibrium constant, respectively. The values of $\Delta H^{\circ}$ and $\Delta S^{\circ}$ were obtained from van't Hoff's plot (equation (10)) of $\ln b$ versus $1 / T$ and are tabulated in Table 5. Gibb's free energy $\left(\Delta G^{\circ}\right)$ of the adsorption process at all temperatures was found to be negative, which indicates that the sorption of $\mathrm{Ni}$ (II) was spontaneous [25]. This further signifies the feasibility of the adsorption reaction. The positive value of enthalpy change $\left(\Delta H^{\circ}\right)$ indicates the endothermic nature of the adsorption process, which is substantiated by the increase in the sorption capacity with
TABLE 5: Thermodynamic parameters for the adsorption of Ni (II) onto sawdust.

\begin{tabular}{lccc}
\hline$T(\mathrm{~K})$ & $\Delta G^{\circ}(\mathrm{kJ} / \mathrm{mol})$ & $\Delta H^{\circ}(\mathrm{kJ} / \mathrm{mol})$ & $\Delta S^{\circ}(\mathrm{kJ} /(\mathrm{mol} \cdot \mathrm{K}))$ \\
\hline 298 & -6.434 & & \\
308 & -6.763 & 2.865 & 0.0312 \\
318 & -7.057 & & \\
\hline
\end{tabular}

the temperature rise. The value of entropy change $\left(\Delta S^{\circ}\right)$ was positive too, which indicates high randomness at the adsorbent-adsorbate interface during the adsorption of nickel ions on sawdust.

\section{Conclusions}

In this study, the mahogany sawdust, a locally available and cheap material, is applied as a biosorbent (after simple chemical treatment) for the removal of nickel ions (Ni (II)) from an aqueous solution. The kinetic studies specified that the equilibrium state in the adsorption of nickel ions on sawdust was reached in $120 \mathrm{~min}$ of contact between the adsorbate and adsorbent at a stirring speed of $200 \mathrm{rpm}$. In addition, based on the correlation coefficient value $\left(R^{2}\right)$, it was found that adsorption kinetics fitted better in the pseudo-second-order model compared to the pseudo-firstorder model. Multistage adsorption (external surface adsorption and intraparticle diffusion) was supposed to occur. Based on the sorption isotherm fitting analysis, the adsorption of $\mathrm{Ni}$ (II) on treated mahogany sawdust follows the Langmuir model, which indicates monolayer adsorption. The maximum sorption capacity was calculated to be $13.42 \mathrm{mg} / \mathrm{g}$. Thermodynamic studies showed that higher sorption temperature was more favorable. The calculated values of thermodynamic parameters implied that the adsorption process was spontaneous and endothermic. In the end, considering the abundance, availability, and low cost of sawdust, along with the presented results, it can be concluded that the investigated biosorbent (mahogany sawdust) is suitable for and effective in removing nickel ions from aqueous solution.

\section{Data Availability}

All data generated through experiments and/or analyzed during this study are included in this article as well as in the Supplementary Materials. 


\section{Disclosure}

This research was performed as part of the employment at Jashore University of Science and Technology.

\section{Conflicts of Interest}

The authors declare that they have no known competing financial interests or personal relationships that could have appeared to influence the work reported in this article.

\section{Supplementary Materials}

Figure S1: FTIR spectra of (i) raw sawdust, (ii) treated sawdust, and (iii) spent sawdust. Nickel removal from aqueous solution by chemically treated mahogany sawdust adsorbent is linked with functional groups present in the adsorbent. Figure S1 describes the absorbance spectra of raw sawdust, treated sawdust, and spent sawdust within the wavenumber range of $4000-400 \mathrm{~cm}^{-1}$. The spectra were used to evaluate the rearrangement of chemical bonds as well as the change in structures of sawdust. It is observed from this figure that some wavenumbers slightly deviate after the adsorption process. This is the indication of nickel adsorption by the adsorbent through a metal-binding process. Figure S2: point of zero charge of chemically treated mahogany sawdust. The point of zero charge $\left(\mathrm{pH}_{\mathrm{pzc}}\right)$ provides important information about the adsorbent surface charge, which might be helpful for understanding the adsorption mechanism. The $\mathrm{pH}_{\mathrm{pzc}}$ can be defined as the $\mathrm{pH}$ at which the net charge of an adsorbent surface is zero. Figure S2 demonstrates the point of zero charge of the adsorbent (chemically treated mahogany sawdust). The $\mathrm{pH}_{\mathrm{pzc}}$ was determined to be 6.8. It signifies that the adsorbent surface has positive charge at a solution $\mathrm{pH}$ less than $\mathrm{pH}_{\mathrm{pzc}}$ and the surface is supposed to adsorb negatively charged anions. On the contrary, the adsorbent surface has negative charge at a solution $\mathrm{pH}$ higher than $\mathrm{pH}_{\mathrm{pzc}}$, and the adsorbent adsorbs positively charged cations. It is evident from experiments that nickel removal significantly increases at $\mathrm{pH}$ higher than the $\mathrm{pH}_{\mathrm{pzc}}$. (Supplementary Materials)

\section{References}

[1] O. A. Oyewo, B. Mutesse, T. Y. Leswifi, and M. S. Onyango, "Highly efficient removal of nickel and cadmium from water using sawdust-derived cellulose nanocrystals," Journal of Environmental Chemical Engineering, vol. 7, no. 4, Article ID 103251, 2019.

[2] M. Rafatullah, O. Sulaiman, R. Hashim, and A. Ahmad, "Adsorption of copper (II), chromium (III), nickel (II) and lead (II) ions from aqueous solutions by meranti sawdust," Journal of Hazardous Materials, vol. 170, no. 2-3, pp. 969-977, 2009.

[3] Y. Wu, H. Luo, H. Wang, L. Zhang, P. Liu, and L. Feng, "Fast adsorption of nickel ions by porous graphene oxide/sawdust composite and reuse for phenol degradation from aqueous solutions," Journal of Colloid and Interface Science, vol. 436, pp. 90-98, 2014.

[4] M. A. Khan, A. A. Alqadami, M. Otero et al., "Heteroatomdoped magnetic hydrochar to remove post-transition and transition metals from water: synthesis, characterization, and adsorption studies," Chemosphere, vol. 218, pp. 1089-1099, 2019.

[5] A. Öztürk, T. Artan, and A. Ayar, "Biosorption of nickel (II) and copper (II) ions from aqueous solution by Streptomyces coelicolor A3(2)," Colloids and Surfaces B: Biointerfaces, vol. 34, no. 2, pp. 105-111, 2004.

[6] N. Sharma, K. Kaur, and S. Kaur, "Kinetic and equilibrium studies on the removal of $\mathrm{Cd} 2+$ ions from water using polyacrylamide grafted rice (Oryza sativa) husk and (Tectona grandis) saw dust," Journal of Hazardous Materials, vol. 163, no. 2-3, pp. 1338-1344, 2009.

[7] S. A. Maddodi, H. A. Alalwan, A. H. Alminshid, and M. N. Abbas, "Isotherm and computational fluid dynamics analysis of nickel ion adsorption from aqueous solution using activated carbon," South African Journal of Chemical Engineering, vol. 32, pp. 5-12, 2020.

[8] D. Bulgariu and L. Bulgariu, "Equilibrium and kinetics studies of heavy metal ions biosorption on green algae waste biomass," Bioresource Technology, vol. 103, no. 1, pp. 489-493, 2012.

[9] A. A. Alqadami, M. A. Khan, M. R. Siddiqui, and Z. A. Alothman, "Development of citric anhydride anchored mesoporous MOF through post synthesis modification to sequester potentially toxic lead (II) from water," Microporous and Mesoporous Materials, vol. 261, pp. 198-206, 2018.

[10] S. Rengaraj, C. K. Joo, Y. Kim, and J. Yi, "Kinetics of removal of chromium from water and electronic process wastewater by ion exchange resins: $1200 \mathrm{H}, 1500 \mathrm{H}$ and IRN97H," Journal of Hazardous Materials, vol. 102, no. 2-3, pp. 257-275, 2003.

[11] V. Hasija, P. Raizada, P. Singh et al., "Progress on the photocatalytic reduction of hexavalent $\mathrm{Cr}$ (VI) using engineered graphitic carbon nitride," Process Safety and Environmental Protection, vol. 152, pp. 663-678, 2021.

[12] Y. C. Sharma, B. Singh, A. Agrawal, and C. H. Weng, "Removal of chromium by riverbed sand from water and wastewater: effect of important parameters," Journal of Hazardous Materials, vol. 151, no. 2-3, pp. 789-793, 2008.

[13] A. Hariharan, V. Harini, S. Sandhya, and S. Rangabhashiyam, "Waste Musa acuminata residue as a potential biosorbent for the removal of hexavalent chromium from synthetic wastewater," Biomass Conversion and Biorefinery, 2020.

[14] B. K. Biswas, K. Inoue, K. N. Ghimire, H. Kawakita, K. Ohto, and H. Harada, "Effective removal of arsenic with lanthanum (III)- and cerium (III)-loaded orange waste gels," Separation Science and Technology, vol. 43, no. 8, pp. 2144-2165, 2008.

[15] M. Tsuji, “'SeO32-selective properties of inorganic materials synthesized by the soft chemical process," Solid State Ionics, vol. 151, no. 1-4, pp. 385-392, 2002.

[16] R. Chand, T. Watari, K. Inoue, T. Torikai, and M. Yada, "Evaluation of wheat straw and barley straw carbon for $\mathrm{Cr}$ (VI) adsorption," Separation and Purification Technology, vol. 65, no. 3, pp. 331-336, 2009.

[17] C. Raj Adhikari, D. Parajuli, H. Kawakita, K. Inoue, K. Ohto, and D. Fujiwara, "Adsorption behavior of iminodiacetic acid type of chelating gel prepared from waste paper," Separation Science and Technology, vol. 42, no. 3, pp. 579-590, 2007.

[18] A. Das, N. Bar, and S. K. Das, "Pb (II) adsorption from aqueous solution by nutshells, green adsorbent: adsorption studies, regeneration studies, scale-up design, its effect on biological indicator and MLR modeling," Journal of Colloid and Interface Science, vol. 580, pp. 245-255, 2020.

[19] A. Witek-Krowiak, "Application of beech sawdust for removal of heavy metals from water: biosorption and desorption 
studies," European Journal of Wood and Wood Products, vol. 71, no. 2, pp. 227-236, 2013.

[20] M. H. Kalavathy and L. R. Miranda, "Comparison of copper adsorption from aqueous solution using modified and unmodified Hevea brasiliensis saw dust," Desalination, vol. 255, no. 1-3, pp. 165-174, 2010.

[21] V. K. Garg, R. Gupta, A. Bala Yadav, and R. Kumar, "Dye removal from aqueous solution by adsorption on treated sawdust," Bioresource Technology, vol. 89, no. 2, pp. 121-124, 2003.

[22] S. R. Khan, A. Inayat, and A. Rana, "Sorption of reactive and acid dyes from aqueous solutions onto sawdust," Bangladesh Journal of Scientific \& Industrial Research, vol. 45, no. 1, pp. 35-38, 2010.

[23] A. Shukla, Y. H. Zhang, P. Dubey, J. L. Margrave, and S. S. Shukla, "The role of sawdust in the removal of unwanted materials from water," Journal of Hazardous Materials, vol. 95, no. 1-2, pp. 137-152, 2002.

[24] T. K. Naiya, P. Chowdhury, A. K. Bhattacharya, and S. K. Das, "Saw dust and neem bark as low-cost natural biosorbent for adsorptive removal of $\mathrm{Zn}$ (II) and $\mathrm{Cd}(\mathrm{II})$ ions from aqueous solutions," Chemical Engineering Journal, vol. 148, no. 1, pp. $68-79,2009$.

[25] J. Long, X. Huang, X. Fan, Y. Peng, and J. Xia, "Effective adsorption of nickel (II) with Ulva lactuca dried biomass: isotherms, kinetics and mechanisms," Water Science and Technology, vol. 78, no. 1, pp. 156-164, 2018.

[26] Z. A. Alothman, A. H. Bahkali, M. A. Khiyami et al., "Low cost biosorbents from fungi for heavy metals removal from wastewater," Separation Science and Technology, vol. 55, no. 10, pp. 1766-1775, 2020.

[27] L. Gonsalvesh, S. P. Marinov, G. Gryglewicz, R. Carleer, and J. Yperman, "Preparation, characterization and application of polystyrene based activated carbons for $\mathrm{Ni}$ (II) removal from aqueous solution," Fuel Processing Technology, vol. 149, pp. 75-85, 2016.

[28] K. Anoop Krishnan, K. G. Sreejalekshmi, and R. S. Baiju, "Nickel(II) adsorption onto biomass based activated carbon obtained from sugarcane bagasse pith," Bioresource Technology, vol. 102, no. 22, pp. 10239-10247, 2011.

[29] N. Ünlü and M. Ersoz, "Adsorption characteristics of heavy metal ions onto a low cost biopolymeric sorbent from aqueous solutions," Journal of Hazardous Materials, vol. 136, no. 2, pp. 272-280, 2006.

[30] Y. S. Ho and G. McKay, "Sorption of dye from aqueous solution by peat," Chemical Engineering Journal, vol. 70, no. 2 , pp. 115-124, 1998.

[31] C. Pang, Y.-H. Liu, X.-H. Cao et al., "Biosorption of uranium(VI) from aqueous solution by dead fungal biomass of Penicillium citrinum," Chemical Engineering Journal, vol. 170, no. 1, pp. 1-6, 2011.

[32] S. Gupta, S. K. Sharma, and A. Kumar, "Biosorption of Ni(II) ions from aqueous solution using modified Aloe barbadensis Miller leaf powder," Water Science and Engineering, vol. 12, no. 1, pp. 27-36, 2019.

[33] S. Parvin, B. K. Biswas, M. A. Rahman, M. H. Rahman, M. S. Anik, and M. R. Uddin, "Study on adsorption of Congo red onto chemically modified egg shell membrane," Chemosphere, vol. 236, Article ID 124326, 2019.

[34] D. A.O, A. P. Olalekan, A. M. Olatunya, and O. Dada, "Langmuir, Freundlich, temkin and dubinin-radushkevich isotherms studies of equilibrium sorption of $\mathrm{Zn} 2+$ unto phosphoric acid modified rice husk," IOSR Journal of Applied Chemistry, vol. 3, no. 1, pp. 38-45, 2012.
[35] E. Çalışkan and S. Göktürk, "Adsorption characteristics of sulfamethoxazole and metronidazole on activated carbon," Separation Science and Technology, vol. 45, no. 2, pp. 244-255, 2010.

[36] G. Annadurai, R. S. Juang, and D. J. Lee, "Adsorption of heavy metals from water using banana and orange peels," Water Science and Technology, vol. 47, no. 1, pp. 185-190, 2003.

[37] K. Moodley, R. Singh, E. Musapatika, M. Onyango, and A. Ochieng, "Removal of nickel from wastewater using an agricultural adsorbent," WaterSA, vol. 37, no. 1, 2011.

[38] M. Bansal, D. Singh, V. K. Garg, and P. Rose, "Use of agricultural waste for the removal of nickel ions from aqueous solutions: equilibrium and kinetics studies," International Journal of Civil and Environmental Engineering, vol. 3, no. 3, 2009.

[39] N. Chaudhary and C. Balomajumder, "Optimization study of adsorption parameters for removal of phenol on aluminum impregnated fly ash using response surface methodology," Journal of the Taiwan Institute of Chemical Engineers, vol. 45, no. 3, pp. 852-859, 2014.

[40] S. Ratan, I. Singh, J. Sarkar, and N. RM, "The removal of nickel from waste water by modified coconut coir pith," Chemical Sciences Journal, vol. 7, no. 3, 2016.

[41] T. W. Weber and R. K. Chakravorti, "Pore and solid diffusion models for fixed-bed adsorbers," AIChE Journal, vol. 20, no. 2, pp. 228-238, 1974.

[42] M. Arami, N. Yousefi Limaee, and N. M. Mahmoodi, "Investigation on the adsorption capability of egg shell membrane towards model textile dyes," Chemosphere, vol. 65, no. 11, pp. 1999-2008, 2006.

[43] A. Adewuyi, "Chemically modified biosorbents and their role in the removal of emerging pharmaceutical waste in the water system," Water, vol. 12, no. 6, pp. 1551-1631, 2020. 